\title{
Similarity between Fourier transforms of objects predicts their experimental confusions
}

\author{
ILIA A. VOL \\ Agrophysical Research Institute, Leningrad, USSR \\ and
}

MARINA B. PAVLOVSKAJA and VALERIJA M. BONDARKO

Pavlov Institute of Physiology of the Academy of Sciences of the USSR, Leningrad, USSR

\begin{abstract}
Two sets of stimuli were presented tachistoscopically to 4 subjects. On each trial, a single stimulus was presented, and the subject was required to identify the stimulus by verbal response. An exposure duration was chosen such that the subject's identification performance fell within a range from faultless identification to chance guessing. The object-identification data of each subject obtained for all stimulus exposures were pooled to form an object confusion matrix. A model of visual processing based on two-dimensional spatial frequency content (Fourier transforms) was used to predict confusions among stimulus pairs. The model properties that appear to be the most essential are those that allow it (1) to account for the obvious dependence of the Fourier transform on the choice of an origin point; and (2) choose the point of origin for each object separately, irrespective of other objects of the set. The point of origin of the reference frame, in which Fourier transforms are performed, is chosen so as to minimize the low-frequency phase component for each object. A high correlation (up to .96) between confusion matrices and model interobject distances was attained. The results demonstrate that such a distance measure gives a good prediction of object confusability.
\end{abstract}

Beginning with the influential papers of Campbell and Robson (1968) and Blakemore and Campbell (1969), a considerable body of psychophysical evidence has been published which supports the hypothesis that, for threshold detection of visual stimuli, the visual system behaves as if it were composed of a number of independent channels, each tuned to a limited range of frequencies and orientations (Graham \& Nachmias, 1971; Mostafavi \& Sakrison, 1976; Sachs, Nachmias, \& Robson, 1971; Sullivan, Georgeson, \& Oatley, 1972; Wilson \& Bergen, 1979). It has been proposed that the visual system performs a Fourier analysis of objects by filtering two-dimensional components (spatial frequency and orientation) of the spatial distribution of luminance on the retina into the responses of separate channels (Campbell \& Robson, 1968; Glezer, Ivanov, \& Tsherbach, 1973; Maffei \& Fiorentini, 1973; Pollen, Lee, \& Taylor, 1971).

Many psychophysical studies have been devoted to the examination of the hypothesis that the visual system utilizes Fourier transforms of objects. The results of these studies are contradictory, however. On the one hand, Harvey and Gervais (1978), for example, investigated

We wish to thank A. A. Nevskaya, who conducted the experiments with the second stimulus set and also kindly presented her experimental data for modeling. We thank Professor V. D. Glezer for discussion of the paper, and the reviewers for thoughtful and helpful comments. Correspondence may be addressed to Mlia A. Vol, who is presently affiliated with the Laboratory of Mathematical Modeling, Plant Protection Institute, Leningrad-Pushkin, 189620, USSR. a relationship between the Fourier spectra of onedimensional textures ${ }^{1}$ and their perceptual appearance. A Fourier analysis model for prediction of two-dimensional texture discrimination was tested by Caelli (1982). The results of these studies indicate a significant correlation between the spatial frequency content of both one- and two-dimensional textures and their discriminability. Coffin (1978), however, could not predict letter confusion matrices using spatial frequency measures of letter similarity. In his study, alphabetic characters were digitized and Fourier-analyzed according to the usual fast Fourier transform methods. Coffin then calculated a series of betweencharacter correlations in terms of amplitude spectra, full Fourier transforms, and even "raw-letter" correlations. $\mathrm{He}$ used these correlations as a metric of interletter similarity.

We, among others, believe that there were several characteristics of Coffin's modeling that led him to incorrectly reject the spatial frequency model. Thus, Gervais, Harvey, and Roberts (1984) noted that "one feature of correlation that diminishes its usefulness in this context is that it is not sensitive to absolute differences between spectra, only to relative differences" (p. 662). Furthermore, the "relative positions of the characterstheir overlap characteristics-affect their phase spectra relationships, and since Coffin was cross-correlating their full spectra, this must be considered, but was not' (Caelli, 1982, p. 154).

In a recent article, Gervais et al. (1984) reported the development of a model based on Fourier transformed 
letter pairs which correlated well with actual letter confusions. In our opinion, however, it is unlikely that this complicated model could be realized by the neurophysiological mechanisms known at present.

It should be noted that the principle of parsimonious modeling requires that only a minimal number of additional assumptions (over and above the examined hypothesis) are allowed. We proceed from the proposition that the spatial frequency content of visual stimuli plays an important role in perception, and that pattern detection may therefore be based on the analysis of this information. Support for such a proposition comes from the neurophysiological data that under certain conditions in the striate cortex, several linear receptive fields (RF) can be revealed in which responses are proportional to convolution over the limited RF area of the stimulus luminance function with trigonometrical (sine and cosine) or Gabor-like RF weighting functions (Andrews \& Pollen, 1979; K. K. De Valois, R. L. De Valois, \& Yund, 1979; Field \& Tolhurst, 1986; Glezer, 1985; Glezer, Tsherbach, Gauzelman, \& Bondarko, 1980; Kulikowski \& Bishop, 1981; Marčelja, 1980; Movshon, Thompson, \& Tolhurst, 1978; Pollen, Foster, \& Gaska, 1985; Pollen \& Ronner, 1982). These cell responses correspond, therefore, to the coefficients of a local Fourier processing that is performed on a limited area comparable to the RF in size. It should be noted that, in the case of the local Fourier analysis, the spatial frequency bandwidth of RF might be rather broad (approximately 1 octave). This is in good accordance with the experimental data (Glezer, 1985; Glezer, Gauzelman, \& Yakovlev, 1987; Kulikowski \& Bishop, 1981).

We propose that object recognition may consist primarily of a template correlation of these receptive field outputs with stored Fourier representations of known patterns. We shall develop a model in which only information about the full spectrum is taken into account, while such real characteristics of the visual system as input-signal spatial quantization by the photoreceptors, finite sizes of the receptive fields, and the finiteness of the set of their weighting functions are neglected. ${ }^{2}$ We shall investigate whether this model can give a good prediction of the confusability between visually inspected objects. We propose that the more similar the Fourier representations of two patterns are, the more likely they are to be confused. Of course, it is not likely that such a model could predict what the brain actually does, but it does imply what the brain could do if it processed the available information from RF outputs. This is the most that any model can aspire to.

In the Theory section, we develop a measure of psychological distance between Fourier transforms of objects. This measure is then compared with the experimental results on object-confusion probabilities.

The distinctive features of this model that set it apart from other, similar approaches are : (1) it accounts for the obvious dependence of the Fourier transform on the choice of a point of origin; and (2) it implements the choice of the origin point for each object separately, irrespective of other objects of the set.

\section{THEORY}

Distance measure for the psychological image space in terms of object Fourier transforms.

The observers in our experiments were given limited viewing time. Therefore, for lack of stimulus information, there was always a nonzero probability that stimuli $j$ and $k$ would be confused with each other. The term "measure of nearness in the psychological image space" is naturally correlated with the confusability determined by the probability of response $k$, given stimulus $j$. The smaller the distance between the $j$ and $k$ objects, the greater this probability should be. The stated aim of the present study was to find a connection between supposed distances and the spatial frequency content of visual patterns.

The Fourier transform $[\Phi(u, v)]$ of the luminance distribution is completely determined either by its real $[\operatorname{Re} \Phi(u, v)]$ and imaginary $[\operatorname{Im} \Phi(u, v)]$ parts, or by the amplitude $[A(u, v)]$ and the phase $[\varphi(u, v)]$ spectra $(u, v$ $=$ spatial frequencies). These functions are connected by the following equations:

$$
\begin{aligned}
& \Phi(u, v)=A(u, v) \exp \{i \varphi(u, v)\} \\
& \operatorname{Re} \Phi(u, v)=A(u, v) \cos \varphi(u, v) \\
& \operatorname{Im} \Phi(u, v)=A(u, v) \sin \varphi(u, v)
\end{aligned}
$$

In order to calculate the Fourier spectrum, it is necessary to set up the frame of reference in which the corresponding transform is performed. From here on, we consider the Cartesian frame of reference and choose only its origin point. It is known that when the origin of a reference frame is moved, the amplitude spectrum does not change, although the phase spectrum does. In the new frame of reference, the phase spectrum $\left[\varphi^{*}(u, v)\right]$ can be easily expressed by the initial phase spectrum and the coordinates of the new origin point $\left(x_{0}, y_{0}\right)$ :

$$
\varphi^{*}(u, v)=\varphi(u, v)+u x_{0}+v y_{0} .
$$

Expressions for $\operatorname{Im} \Phi(u, v)$ and $\operatorname{Re} \Phi(u, v)$ follow directly from Equations 1 and 2.

The importance of the role the phase spectrum plays in the object-recognition process is currently recognized by various authors (Burgess \& Ghandeharian, 1984; Caelli, 1982; Goodman \& Silvestri, 1970; Oppenheim \& Lim, 1981; Piotrowski, 1981). It follows that a choice of the origin of the reference frame, in which Fourier transform is performed, is of great significance.

It should be noted that, in our experiments, stimulus presentation time excluded the possibility of observer gaze shift (see the Method section). It is known that even in this case the invariant object-shape recognition is performed by the visual system independently of the object location on the retina. Since (as stated above) this recogni- 
tion consists of a template correlation of the image spectrum with stored Fourier representations of known patterns, and no additional transformations are performed here, the information about an origin of the frame of reference should be extracted from the object itself, irrespective of the fixation point of gaze and of other objects of the set. This is the first proposition that is taken as the basis of the interobject spectral distances examined in the present study.

Since the tangent of the phase angle equals the ratio of the imaginary part of the spectrum to the real part, an energy redistribution in favor of the real part results in a minimization of the absolute value of the phase component. The main information about the object shape is conveyed by a few low harmonics of the spectrum (Ginsburg, 1971; Glezer \& Borisova, 1984; Pavlovskaya, Sivjakov, \& Makulov, 1988). For this reason, we suggest that the origin chosen by the visual system should be related to a minimization of the low-frequency (the first, nonzero) phase component. It is known that, in terms of Fourier approximation, the sum of the squares of the odd and even receptive field responses (the amplitude at a given frequency) does not depend on the point of origin. In fact, our choice of origin suggests that a response of the visual receptive fields tuned to low frequencies and performing the sine Fourier transform would be approximately zero. A dimension of RF response vector seems to be diminished by this choice. Furthermore, such an energy redistribution in favor of the real part of the spectrum would improve the signal-to-noise ratio for cosine $R F$.

The recent data obtained by Pollen et al. (1985) and Glezer et al. (1987) show that weighting functions of some cortical receptive fields (spatial frequency filters) are shifted by one-fourth of a period relative to each other. Obviously, such fields could be a pair of filters performing windowed cosine and sine Fourier transforms. The assumed choice of origin might be realized by these fields.

It is known that the phase component is odd-symmetric. It passes through the origin point, thus:

$$
\varphi(u, v)=-\varphi(-u,-v) \text {. }
$$

Minimization of low-frequency phase components will therefore occur if the origin point is chosen such that the partial derivatives of the phase component at the origin vanish:

$$
\left(x_{0}, y_{0}\right)=(x, y):\left\{\begin{array}{l}
\partial / \partial u[\varphi(u, v)+x u+y v]=0 \\
\partial / \partial v[\varphi(u, v)+x u+y v]=0
\end{array}\right.
$$

In terms of the object's image, this origin point corresponds to the luminance centroid, or, in other words, to the point with the coordinates:

$$
\begin{array}{r}
x_{0}=-\frac{\int_{-\infty}^{+\infty} x F(x, y) d x d y}{\int_{-\infty}^{+\infty} \int_{-\infty} F(x, y) d x d y}, \\
y_{0}=-\frac{\int_{-\infty}^{+\infty} y F(x, y) d x d y}{\int_{-\infty}^{+\infty} \int_{-\infty} F(x, y) d x d y} .
\end{array}
$$

A Euclidean distance measure between Fourier transforms of objects may now be introduced in a standard way:

$$
S_{j k}^{2}=\int_{-\infty}^{+\infty}\left\{\operatorname{Re}^{2}\left[\Phi_{j}(u, v)-\Phi_{k}(u, v)\right]+\operatorname{Im}^{2}\left[\Phi_{j}(u, v)-\Phi_{k}(u, v)\right]\right\} d u d v,
$$

where $S_{j k}$ is the distance between the $j$ th and $k$ th objects, $\Phi_{j}$ and $\Phi_{k}$ are their Fourier transforms, and $\mathrm{Re}$ and $\mathrm{Im}$ are the real and the imaginary parts of the complex number. 
This interobject distance therefore does not correspond to the well-known "template overlap model" used by many authors (see, for example, Caelli, Hübner, \& Rentschler, 1986:

$$
S_{j k}^{2}=\min _{x_{0} y_{0}} \int_{-\infty}^{+\infty} \int_{-\infty}^{\operatorname{Re}} \operatorname{Re}^{2}\left[\Phi_{j}\left(u, v, x_{0}, y_{0}\right)-\Phi_{k}(u, v)\right]+\operatorname{Im}^{2}\left[\Phi_{j}\left(u, v, x_{0}, y_{0}\right)-\Phi_{k}(u, v)\right] d u d v .
$$

The difference between Equations 5 and 6 is essential, because the distance measure presented in Equation 5 suggests that in the early stage of image perception, the visual system first performs its filtering operation, and that only afterwards does template correlation of the resulting description with stored representations of known patterns occur.

To make the preference of choosing the origin according to Equation 4 clear, it is useful to discuss other criteria of similar choice based on the minimization of some functional of the phase component $(I)$ as a function of the new origin $\left(x_{0} y_{0}\right)$ :

$$
\begin{aligned}
I_{1}\left(x_{0}, y_{0}\right) & =\int_{-\infty}^{\infty} \int_{-\infty} A(u, v) \sin ^{2} \frac{\varphi^{*}(u, v)}{2} d u d v \\
& =\int_{-\infty}^{\infty} \int_{-\infty} A(u, v) \sin ^{2}\left[\frac{\varphi(u, v)+x_{0} u+y_{0} v}{2}\right] d u d v
\end{aligned}
$$

This functional differs little from that of a weighted square of the phase component $(I)$ :

$$
\tilde{I}\left(x_{0}, y_{0}\right)=\int_{-\infty}^{\infty} \int_{-\infty} A(u, v) \varphi^{2}(u, v) d u d v
$$

but $I_{1}$ allows an analytical investigation. Proceeding from trigonometrical arguments, one may be easily convinced that $I_{1}\left(x_{0}, y_{0}\right)$ reduces to a minimum at the point $\left(x_{0}, y_{0}\right)$, where the following integral reaches a maximum:

$$
\hat{I}_{1}=\int_{-\infty}^{\infty} \int_{\infty} A(u, v) \cos \varphi^{*}(u, v) d u d v .
$$

Since only its principal value ought to be taken into consideration, then (up to a constant multiplier):

$$
\hat{I}_{1}=\int_{-\infty}^{\infty} \int_{-\infty} A(u, v) \exp \left[i \varphi^{*}(u, v)\right] d u d v=F\left(x_{0}, y_{0}\right) ;
$$

that is, in this case, a point with maximal luminance $[F(x, y)]$ would be chosen as the origin of the reference frame. But it is quite possible that there are several points with the same luminance value. Such ambiguous choice seems to be unreasonable.

Let us also consider a frame of reference in which the energy of the imaginary part of the spectrum is minimized:

$$
I_{2}\left(x_{0}, y_{0}\right)=\int_{-\infty}^{\infty} \int_{-\infty}^{2} A^{2}(u, v) \sin ^{2}\left[\varphi(u, v)+v y_{0}+u x_{0}\right] d u d v=\int_{-\infty}^{\infty} \int_{-\infty} \operatorname{Im}^{2} \Phi^{*}(u, v) d u d v,
$$

or, alternatively,

$$
I_{2}\left(x_{0}, y_{0}\right)=0.5 \cdot \int_{-\infty}^{\infty} \int_{-\infty}\left[F\left(x_{0}-x, y_{0}-y\right)-F\left(x_{0}+x, y_{0}+y\right)\right]^{2} d u d v .
$$

It can be seen that when a stimulus consists of two uniformly illuminated same-sized rectangles of which only the parallel sides have different contrasts, $I_{2}$ has three local minima. Two of the minima coincide with the symmetrical centers of the rectangles, while the third coincides with the middle of a line connecting these centers. Then, if one of the contrasts is altered, the origin should change in an uneven manner, making for a seemingly implausible approach for visual analysis. 
It should be noted, however, that some visual illusions might be explained by just such an ambiguity in the choice of an origin.

So we choose the Cartesian frame of a reference of which the origin is positioned in such a way as to minimize the phase of the low-frequency components of each stimulus according to Equation 3. The coordinates of this point and the Euclidean distance measure between Fourier transforms of objects are determined by Equations 4 and 5, respectively.

From the formal point of view, the following operations were performed:

1. The object space was factorized. That is, all objects were classified such that objects which could be superposed by a parallel transfer would be placed in the same class.

2. From each class, one representative was chosen, the luminance centroid of which coincided with the origin.

The separate choice of the spatial origin for each object as proposed here, merely specifies the relative phases of the frequency components of class representatives and hence the Euclidean metric (Equation 5) in the Fourier space as a measure of the distances between these classes.

This distance, which follows from the theory of the Fourier integral, can be easily calculated in the following way: It is necessary to match the luminance centroids of two objects and then to calculate the area of the nonoverlapping parts; the interobject distance will be proportional to the square root of this value. In this way (without spectral calculation), this distance is calculated for one of the sets used-namely, for the first stimulus set (see below); for the second set, the objects were Fourier transformed by the FFT algorithm.

\section{METHOD}

\section{Stimuli and Apparatus}

Two stimulus sets were used in the present experiments. The test stimuli of the first set were images of nine objects (see Table 1). The images were generated by a spectral device-the Optronix Fotomachine Mark II-on a $512 \times 512$ matrix and quantized to 256 linearly distributed gray levels. Each object was a square 30 pixels on a side. The second stimulus set consisted of eight contour figures

Table 1

Comparison of Experimental Results and Model Predictions

STIMULI:

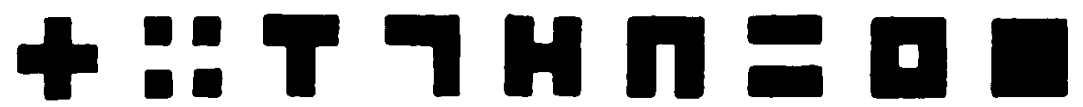

\begin{tabular}{|c|c|c|c|c|c|c|c|c|c|c|c|}
\hline \multirow[b]{2}{*}{ Subjects } & \multirow[b]{2}{*}{ Stimulus } & \multicolumn{9}{|c|}{ Responses } & \multirow{2}{*}{$\begin{array}{c}\text { Number of } \\
\text { Presentations }\end{array}$} \\
\hline & & 1 & 2 & 3 & 4 & 5 & 6 & 7 & 8 & 9 & \\
\hline $\begin{array}{l}\text { N.K. } \\
\text { N.Ch. } \\
\text { Model }\end{array}$ & 1 & $\begin{array}{r}142 \\
176 \\
0\end{array}$ & $\begin{array}{r}16 \\
26 \\
1.0\end{array}$ & $\begin{array}{l}19 \\
21 \\
.60\end{array}$ & $\begin{array}{l}11 \\
17 \\
.72\end{array}$ & $\begin{array}{l}13 \\
27 \\
.82\end{array}$ & $\begin{array}{r}8 \\
10 \\
.82\end{array}$ & $\begin{array}{r}12 \\
23 \\
.88\end{array}$ & $\begin{array}{r}11 \\
3 \\
.74\end{array}$ & $\begin{array}{r}4 \\
41 \\
.67\end{array}$ & $\begin{array}{l}236 \\
344\end{array}$ \\
\hline $\begin{array}{l}\text { N.K. } \\
\text { N.Ch. } \\
\text { Model }\end{array}$ & 2 & $\begin{array}{r}14 \\
24 \\
1.0\end{array}$ & $\begin{array}{r}143 \\
218 \\
0\end{array}$ & $\begin{array}{l}15 \\
30 \\
.86\end{array}$ & $\begin{array}{r}20 \\
18 \\
.81\end{array}$ & $\begin{array}{l}14 \\
45 \\
.58\end{array}$ & $\begin{array}{r}11 \\
16 \\
.63\end{array}$ & $\begin{array}{l}70 \\
55 \\
.47\end{array}$ & $\begin{array}{r}5 \\
4 \\
.67\end{array}$ & $\begin{array}{r}3 \\
20 \\
.74\end{array}$ & $\begin{array}{l}295 \\
430\end{array}$ \\
\hline $\begin{array}{l}\text { N.K. } \\
\text { N.Ch. } \\
\text { Model }\end{array}$ & 3 & $\begin{array}{r}24 \\
33 \\
.60\end{array}$ & $\begin{array}{l}16 \\
35 \\
.86\end{array}$ & $\begin{array}{r}179 \\
173 \\
0\end{array}$ & $\begin{array}{r}25 \\
65 \\
.60\end{array}$ & $\begin{array}{r}9 \\
24 \\
.82\end{array}$ & $\begin{array}{r}14 \\
17 \\
.85\end{array}$ & $\begin{array}{r}14 \\
22 \\
.77\end{array}$ & $\begin{array}{r}5 \\
13 \\
.80\end{array}$ & $\begin{array}{r}9 \\
48 \\
.73\end{array}$ & $\begin{array}{l}295 \\
430\end{array}$ \\
\hline $\begin{array}{l}\text { N.K. } \\
\text { N.Ch. } \\
\text { Model }\end{array}$ & 4 & $\begin{array}{r}6 \\
23 \\
.72\end{array}$ & $\begin{array}{l}11 \\
35 \\
.81\end{array}$ & $\begin{array}{r}30 \\
48 \\
.60\end{array}$ & $\begin{array}{r}176 \\
217 \\
0\end{array}$ & $\begin{array}{l}12 \\
33 \\
.79\end{array}$ & $\begin{array}{r}28 \\
19 \\
.76\end{array}$ & $\begin{array}{r}12 \\
21 \\
.81\end{array}$ & $\begin{array}{r}14 \\
8 \\
.81\end{array}$ & $\begin{array}{r}6 \\
26 \\
.79\end{array}$ & $\begin{array}{l}295 \\
430\end{array}$ \\
\hline $\begin{array}{l}\text { N.K } \\
\text { N.Ch. } \\
\text { Model }\end{array}$ & 5 & $\begin{array}{r}5 \\
20 \\
.82\end{array}$ & $\begin{array}{l}25 \\
17 \\
.58\end{array}$ & $\begin{array}{r}6 \\
30 \\
.82\end{array}$ & $\begin{array}{r}9 \\
20 \\
.79\end{array}$ & $\begin{array}{r}154 \\
203 \\
0\end{array}$ & $\begin{array}{l}45 \\
44 \\
.50\end{array}$ & $\begin{array}{l}15 \\
16 \\
.74\end{array}$ & $\begin{array}{l}14 \\
12 \\
.58\end{array}$ & $\begin{array}{l}22 \\
68 \\
.47\end{array}$ & $\begin{array}{l}295 \\
430\end{array}$ \\
\hline $\begin{array}{l}\text { N.K. } \\
\text { N.Ch. } \\
\text { Model }\end{array}$ & 6 & $\begin{array}{r}3 \\
15 \\
.82\end{array}$ & $\begin{array}{r}8 \\
16 \\
.63\end{array}$ & $\begin{array}{r}8 \\
44 \\
.85\end{array}$ & $\begin{array}{l}27 \\
20 \\
.76\end{array}$ & $\begin{array}{l}29 \\
68 \\
.50\end{array}$ & $\begin{array}{r}148 \\
158 \\
0\end{array}$ & $\begin{array}{r}6 \\
12 \\
.65\end{array}$ & $\begin{array}{r}38 \\
33 \\
.45\end{array}$ & $\begin{array}{l}28 \\
64 \\
.53\end{array}$ & $\begin{array}{l}295 \\
430\end{array}$ \\
\hline $\begin{array}{l}\text { N.K. } \\
\text { N.Ch. } \\
\text { Model }\end{array}$ & 7 & $\begin{array}{r}6 \\
25 \\
.88\end{array}$ & $\begin{array}{l}19 \\
37 \\
.47\end{array}$ & $\begin{array}{l}32 \\
44 \\
.77\end{array}$ & $\begin{array}{r}41 \\
33 \\
.81\end{array}$ & $\begin{array}{r}5 \\
33 \\
.74\end{array}$ & $\begin{array}{r}7 \\
22 \\
.65\end{array}$ & $\begin{array}{r}165 \\
207 \\
0\end{array}$ & $\begin{array}{r}9 \\
5 \\
.47\end{array}$ & $\begin{array}{r}11 \\
24 \\
.58\end{array}$ & $\begin{array}{l}295 \\
430\end{array}$ \\
\hline $\begin{array}{l}\text { N.K. } \\
\text { N.Ch. } \\
\text { Model }\end{array}$ & 8 & $\begin{array}{l}12 \\
15 \\
.74\end{array}$ & $\begin{array}{l}11 \\
12 \\
.67\end{array}$ & $\begin{array}{r}6 \\
16 \\
.80\end{array}$ & $\begin{array}{r}10 \\
8 \\
.81\end{array}$ & $\begin{array}{l}28 \\
73 \\
.58\end{array}$ & $\begin{array}{r}47 \\
48 \\
.45\end{array}$ & $\begin{array}{r}9 \\
14 \\
.47\end{array}$ & $\begin{array}{r}120 \\
135 \\
0\end{array}$ & $\begin{array}{r}52 \\
109 \\
.33\end{array}$ & $\begin{array}{l}295 \\
430\end{array}$ \\
\hline $\begin{array}{l}\text { N.K. } \\
\text { N.Ch. } \\
\text { Model }\end{array}$ & 9 & $\begin{array}{r}9 \\
13 \\
.67 \\
\end{array}$ & $\begin{array}{r}23 \\
7 \\
.74\end{array}$ & $\begin{array}{r}4 \\
23 \\
.73 \\
\end{array}$ & $\begin{array}{r}6 \\
13 \\
.79 \\
\end{array}$ & $\begin{array}{r}43 \\
80 \\
.47 \\
\end{array}$ & $\begin{array}{l}29 \\
49 \\
.53\end{array}$ & $\begin{array}{l}10 \\
17 \\
.58 \\
\end{array}$ & $\begin{array}{r}60 \\
34 \\
.33 \\
\end{array}$ & $\begin{array}{r}111 \\
194 \\
0\end{array}$ & $\begin{array}{l}295 \\
430\end{array}$ \\
\hline
\end{tabular}

Note-The values are the number of $k$ answers, when stimulus $j$ was given, and the model distances between the objects $j$ and $k$ ( $j$ th line, $k$ th column). 
Table 2

Comparison of Experimental Results and Model Predictions

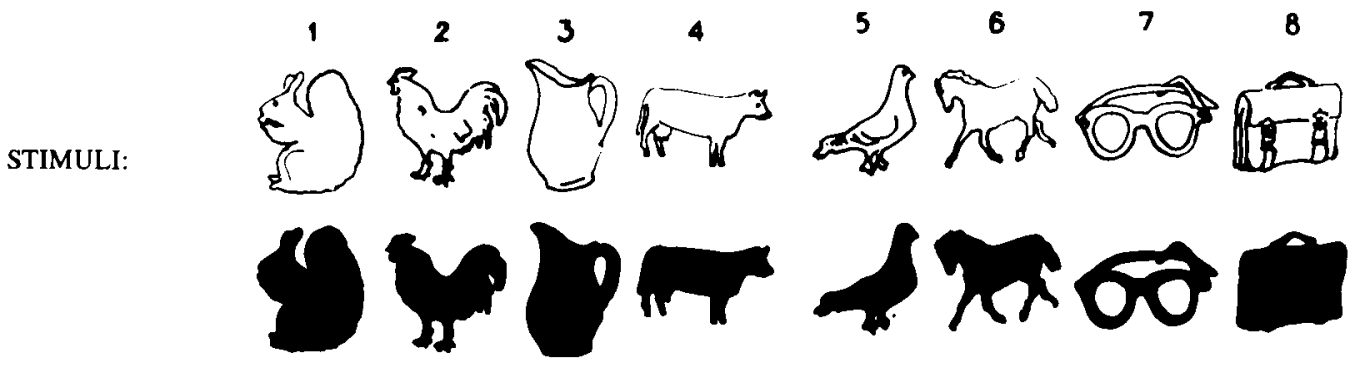

\begin{tabular}{|c|c|c|c|c|c|c|c|c|c|c|c|}
\hline \multirow[b]{2}{*}{ Subjects } & \multirow[b]{2}{*}{ Stimulus } & \multicolumn{8}{|c|}{ Responses } & \multirow{2}{*}{$\begin{array}{c}\text { "I Don't Know" } \\
\text { Answers }\end{array}$} & \multirow{2}{*}{$\begin{array}{l}\text { Number of } \\
\text { Presentations }\end{array}$} \\
\hline & & 1 & 2 & 3 & 4 & 5 & 6 & 7 & 8 & & \\
\hline $\begin{array}{l}\text { A.E. } \\
\text { I.E. } \\
\text { Model }\end{array}$ & 1 & $\begin{array}{r}850 \\
403 \\
0\end{array}$ & $\begin{array}{r}132 \\
59 \\
.8\end{array}$ & $\begin{array}{r}145 \\
55 \\
.67\end{array}$ & $\begin{array}{l}62 \\
20 \\
.89\end{array}$ & $\begin{array}{l}37 \\
18 \\
.98\end{array}$ & $\begin{array}{l}80 \\
29 \\
.84\end{array}$ & $\begin{array}{r}52 \\
32 \\
1\end{array}$ & $\begin{array}{l}82 \\
37 \\
.71\end{array}$ & 163 & $\begin{array}{r}1440 \\
816\end{array}$ \\
\hline $\begin{array}{l}\text { A.E. } \\
\text { I.E. } \\
\text { Model }\end{array}$ & 2 & $\begin{array}{r}138 \\
37 \\
.8\end{array}$ & $\begin{array}{r}920 \\
393 \\
0\end{array}$ & $\begin{array}{l}86 \\
40 \\
.73\end{array}$ & $\begin{array}{l}64 \\
37 \\
.72\end{array}$ & $\begin{array}{l}54 \\
28 \\
.83\end{array}$ & $\begin{array}{l}66 \\
40 \\
.74\end{array}$ & $\begin{array}{r}31 \\
25 \\
.9\end{array}$ & $\begin{array}{l}81 \\
43 \\
.78\end{array}$ & 173 & $\begin{array}{r}1440 \\
816\end{array}$ \\
\hline $\begin{array}{l}\text { A.E. } \\
\text { I.E. } \\
\text { Model }\end{array}$ & 3 & $\begin{array}{r}172 \\
31 \\
.67\end{array}$ & $\begin{array}{r}160 \\
52 \\
.73\end{array}$ & $\begin{array}{r}808 \\
394 \\
0\end{array}$ & $\begin{array}{r}57 \\
23 \\
.85\end{array}$ & $\begin{array}{r}49 \\
21 \\
.8\end{array}$ & $\begin{array}{l}67 \\
30 \\
.84\end{array}$ & $\begin{array}{r}44 \\
32 \\
.9\end{array}$ & $\begin{array}{l}83 \\
55 \\
.76\end{array}$ & 178 & $\begin{array}{r}1440 \\
816\end{array}$ \\
\hline $\begin{array}{l}\text { A.E. } \\
\text { I.E. } \\
\text { Model }\end{array}$ & 4 & $\begin{array}{l}62 \\
27 \\
.89\end{array}$ & $\begin{array}{l}85 \\
35 \\
.72\end{array}$ & $\begin{array}{l}59 \\
18 \\
.85\end{array}$ & $\begin{array}{r}969 \\
462 \\
0\end{array}$ & $\begin{array}{r}63 \\
33 \\
.63\end{array}$ & $\begin{array}{l}66 \\
23 \\
.71\end{array}$ & $\begin{array}{l}41 \\
27 \\
.81\end{array}$ & $\begin{array}{l}95 \\
34 \\
.75\end{array}$ & 157 & $\begin{array}{r}1440 \\
816\end{array}$ \\
\hline $\begin{array}{l}\text { A.E. } \\
\text { I.E. } \\
\text { Model }\end{array}$ & 5 & $\begin{array}{r}125 \\
31 \\
.98\end{array}$ & $\begin{array}{r}188 \\
43 \\
.83\end{array}$ & $\begin{array}{r}106 \\
39 \\
.80\end{array}$ & $\begin{array}{l}69 \\
35 \\
.63\end{array}$ & $\begin{array}{r}765 \\
409 \\
0\end{array}$ & $\begin{array}{l}71 \\
33 \\
.72\end{array}$ & $\begin{array}{l}51 \\
34 \\
.9\end{array}$ & $\begin{array}{r}65 \\
27 \\
.9\end{array}$ & 165 & $\begin{array}{r}1440 \\
816\end{array}$ \\
\hline $\begin{array}{l}\text { A.E. } \\
\text { I.E. } \\
\text { Model }\end{array}$ & 6 & $\begin{array}{r}168 \\
40 \\
.84\end{array}$ & $\begin{array}{r}179 \\
61 \\
.74\end{array}$ & $\begin{array}{r}158 \\
33 \\
.84\end{array}$ & $\begin{array}{r}129 \\
63 \\
.71\end{array}$ & $\begin{array}{r}77 \\
36 \\
.72\end{array}$ & $\begin{array}{r}560 \\
266 \\
0\end{array}$ & $\begin{array}{l}63 \\
38 \\
.85\end{array}$ & $\begin{array}{r}106 \\
57 \\
.74\end{array}$ & 222 & $\begin{array}{r}1440 \\
816\end{array}$ \\
\hline $\begin{array}{l}\text { A.E. } \\
\text { I.E. } \\
\text { Model }\end{array}$ & 7 & $\begin{array}{r}98 \\
30 \\
1\end{array}$ & $\begin{array}{r}117 \\
38 \\
.9\end{array}$ & $\begin{array}{r}73 \\
30 \\
.9\end{array}$ & $\begin{array}{l}71 \\
31 \\
.81\end{array}$ & $\begin{array}{r}68 \\
22 \\
.9\end{array}$ & $\begin{array}{l}89 \\
32 \\
.85\end{array}$ & $\begin{array}{r}867 \\
423 \\
0\end{array}$ & $\begin{array}{l}57 \\
32 \\
.87\end{array}$ & 178 & $\begin{array}{r}1440 \\
816\end{array}$ \\
\hline $\begin{array}{l}\text { A.E. } \\
\text { I.E. } \\
\text { Model }\end{array}$ & 8 & $\begin{array}{r}133 \\
38 \\
.71\end{array}$ & $\begin{array}{r}117 \\
37 \\
.78\end{array}$ & $\begin{array}{r}111 \\
38 \\
.76\end{array}$ & $\begin{array}{r}135 \\
56 \\
.75\end{array}$ & $\begin{array}{l}59 \\
15 \\
.9\end{array}$ & $\begin{array}{l}75 \\
42 \\
.74\end{array}$ & $\begin{array}{r}41 \\
26 \\
.87\end{array}$ & $\begin{array}{r}769 \\
397 \\
0\end{array}$ & 167 & $\begin{array}{r}1440 \\
816\end{array}$ \\
\hline
\end{tabular}

Note-The values are the number of $k$ answers, when stimulus $j$ was given, and the model distances between the objects $j$ and $k$ ( $j$ th line, $k$ th column).

(see Table 2, top row). All images were printed on Polaroid film and then copied.

A two-channel tachistoscope was used to control the presentation of a masking stimulus and a stimulus field containing a randomly selected object. The masking field for the first stimulus set consisted of white and black squares, which were randomly distributed over the field of vision, their sizes corresponding to the object size, for the second set, a mask was an irregular array of various image contours.

The object was centered in the circular field of the tachistoscope. Each stimulus of the first set subtended $25^{\prime}$ and $1.64^{\circ}$ of visual angle in the first and second experiments, respectively. Object size of the second stimulus set was $3^{\circ}$ of visual angle. The luminance of the white background was $10.0 \mathrm{~cd} / \mathrm{m}^{2}$; the black objects had a relative contrast of .65 .

\section{Subjects}

Four subjects (staff members of the Physiology Department) participated in the experiment. All the subjects were emmetropic naive volunteers. Two of them dealt with the first stimulus set and 2 with the second. Each subject was acquainted with the set of objects that could be shown to him.

\section{Procedure}

For each trial, the stimulus sequence was as follows: masking field; ready tone, given by the experimenter; buttonpress by the observer to initiate the trial; stimulus field for a predetermined exposure duration; masking field. To determine the range of exposure durations that would permit an identification performance ranging from faultless identification to chance guessing, each subject participated in several calibration sessions. For all subjects, this range was from 140 to $10 \mathrm{msec}$. After each stimulus presentation, the subject made a verbal identification response regarding the object shape; "I don't know" answers were allowed only for Observer I.E. (see Table 2). The subjects' answers, both incorrect and correct, were recorded.

Each subject was tested in several experimental sessions; the number of stimulus presentations was varied from 240 to 1,440 . The order of presentation was quasirandom and was determined for each session by shuffling the stimulus set. Each session lasted approxi- 
mately $1 \mathrm{~h}$. The object-identification data obtained for each subject and for all stimulus exposures were pooled to form an object confusion matrix.

\section{RESULTS AND DISCUSSION}

To compare the obtained results and model predictions concerning psychological distances, linear correlation (Pearson's $r$ ) between elements of the object confusion matrix and model distances was calculated.

The correspondence matrices of 2 subjects and the first stimulus set (object size, $25^{\prime}$ ) are given in Table 1. It shows the number of $k$ answers when stimulus $j$ was given, and the model distances between the objects $j$ and $k$ ( $j$ th line, $k$ th column). The obtained correlations for full matrices were -.88 and -.86 for each subject, respectively. It appeared that a change in object size (up to $1.64^{\circ}$ ) did not affect the result appreciably; the correlations were in this case equally high: -.86 and -.81 . All these correlations are highly significant $(p<.001)$. It is possible that such a high correlation is due to a prevalence of the number of the correct responses to which the minimal (zero) model distances correspond (see matrix diagonal). To test this, selected correlations were calculated for matrices of only wrong answers. In this case, the correlations were naturally lower ( -.48 and -.47 for an object size of $25^{\prime}$; -.48 and -.22 for an object size of $1.64^{\circ}$ ), but they were still highly significant $(p<.001)$. Table 3 summarizes these results.

The validity of the model considered was also tested for the second stimulus set (contour figures). Here it should be noted that the proposed interobject distance measure (see Equation 5) may be introduced in the other way:

$$
S_{j k}^{2}=\int_{-\infty}^{\infty} \int_{j}\left[F_{j}(x, y)-F_{k}(x, y)\right]^{2} d x d y
$$

where $F_{j}, F_{k}$ are the luminance functions of the $j$ th and $k$ th objects where their luminance centroids coincide. Therefore, the distance between figures without common contours (as in our case) will be proportional to the sum of squares of the contours' lengths. That is why direct application of the concept (Equation 5) to the analysis of the contour stimuli (see Table 2, top row) resulted in very low correlations for full matrices: -.21 and -.27 .

One may suggest that the visual system, when analyzing contour figures, does not process information only about contours. Rather, the contour seems to be only an artificial boundary, by means of which a figure-ground separation is performed. It is possible that, for the recognition and discrimination of contour figures, the visual system simply takes into account the information about the object depicted, perhaps on the basis of the spectral content of the filled-in version of the figure. ${ }^{3}$

To test this proposition, we filled in our contour figures (see Table 2, bottom row) and calculated new distances between the filled objects. These model distances are given in Table 2 . The obtained correlations are -.94 and
Table 3

Correlation (Pearson's r) Between Experimental Confusion Matrices and Model Interobject Distances for Different Subjects and Stimulus Sets

\begin{tabular}{llll}
\hline & \multicolumn{3}{c}{ Object Size* } \\
\cline { 2 - 4 } & $0.42^{\circ}$ & $1.64^{\circ}$ & $3.0^{\circ}$ \\
\hline
\end{tabular}

Stimulus Set 1 (see Table 1)

$\begin{array}{lll}\text { N.K. } & \frac{.88}{.48} & \frac{.86}{.48} \\ \text { N.Ch. } & \frac{.86}{.47} & \frac{.81}{.22}\end{array}$

Stimulus Set 2 (see Table 2)

$\begin{array}{lr}\text { A.E. } & \frac{.94}{.31} \\ \text { I.E. } & \frac{.96}{.49}\end{array}$

Note-The values are correlations for the full experimental matrix and for the matrix of only wrong answers (the numerator and the denominator, respectively). *In degrees of visual angle.

-.96 for full matrices and -.31 and -.49 for matrices of only wrong answers for Observers A.E. and I.E., respectively (see Table 3 ). All these correlations are again highly significant.

Thus, all the results provide evidence that interobject distance based on Fourier transforms can give a good prediction of object confusability. These transforms are performed in a frame of reference "tied" to the object itself. The obtained correlations between full confusion matrices and model predictions are close to the data for two-dimensional textures and letters of the alphabet in the Caelli (1982) and Gervais et al. (1984) studies, respectively. Unfortunately, it is impossible to compare data for matrices of wrong answers only, because they are absent in Caelli's paper, and Gervais et al. analyzed symmetrical matrices excluding rates with one or two zero confusion probabilities.

When we tried to convert the raw confusion matrices into symmetrical similarity matrices, as did Gervais et al. (1984) in accordance with Luce's (1963) model, the correlations in most cases improved to the $.60-.70$ range (see Table 4). These results are not significantly worse than those in Gervais et al.'s spatial frequency model (.70); they are better than those in our model (the cases without diagonal elements; see Table 3 ) and those in Gervais et al.'s template overlap model (.5).

We believe, however, that it would be unreasonable to convert the stochastic confusion matrix into a symmetrical similarity matrix. Our model suggests that there is a Euclidean space of responses of the visual system on all possible objects. Each object is represented in this space as a certain point. The system response to the presented object is a point in this space too. A mutual spacing of these points-namely, of the point representing the system response and the points corresponding to set imagesdetermines an observer's answer about the stimulus. Con- 
Table 4

Correlation Between Symmetrical Experimental Confusion Matrices and Model Interobject Distances

\begin{tabular}{|c|c|c|c|}
\hline \multirow[b]{2}{*}{ Subject } & \multicolumn{3}{|c|}{ Object Size* } \\
\hline & $0.42^{\circ}$ & $1.64^{\circ}$ & $3.0^{\circ}$ \\
\hline \multicolumn{4}{|c|}{ Stimulus Set 1-Symmetrical Matrix } \\
\hline \multirow{2}{*}{ N.K. } & 0.88 & 0.92 & \\
\hline & $\overline{0.59}$ & $\overline{0.70}$ & \\
\hline \multirow{2}{*}{ N.Ch. } & 0.85 & 0.9 & \\
\hline & $\overline{0.21}$ & $\overline{0.59}$ & \\
\hline \multicolumn{4}{|c|}{ Stimulus Set 2} \\
\hline \multirow{2}{*}{ A.E. } & & & 0.96 \\
\hline & & & $\overline{0.49}$ \\
\hline \multirow{2}{*}{ I.E. } & & & 0.97 \\
\hline & & & $\overline{0.57}$ \\
\hline
\end{tabular}

*In degrees of visual angle.

sequently, a probability measure of this response point determines the confusion matrix. In the simplest case, the observer names the image that is one of those nearest to the response point.

It follows from these considerations that the confusion matrix will be nonsymmetrical even in the case of onedimensional space: $P_{k j} \neq P_{j k}$ (see Figure 1 , where this space is shown). If response bias were to be introduced in a multiplicative manner, as done in the Luce model, then the confusion matrix could not be symmetrized either, since, in the case of a 12-element confusion matrix ( $e_{i j}$; $i, j=1,2,3,4 ; i \neq j)$, we deal with only 6 measures of similarity $\left(\eta_{i j} ; i, j=1,2,3,4 ; i \neq j ; \eta_{i j}=\eta_{j i}\right)$ and 4 bias response factors $\left(p_{k} k=1, \ldots, 4\right)$ for symmetrization. Thus, the system of 12 Luce's equations for similarity measure and response bias would not be satisfied, and the confusion matrix would not be symmetrized, because the stimulus spacing is rather arbitrary and the correct identification probability depends on the structure of the alphabet-that is, on the distance between the presented stimulus and the other stimuli (see Figure 1).

There follows from this the obvious significance of the diagonal values and the necessity to analyze the raw confusion matrix, excluding neither diagonal values nor rates with one or two zero confusion probabilities. It seems, therefore, that it is reasonable to introduce a bias response factor proceeding from the following model: Observer response should be based on a mixture of two probability distributions, one conditioned by both the presented stimulus and the alphabet structure (i.e., mutual spacing of images in the Euclidean response space $\left(\psi_{i j}\right)$, and the other conditioned by the bias response vector $\left(e_{J}\right)$ :

$$
P_{i j}=[1-\alpha(t)] \psi_{i j}+\alpha(t) Q_{j} .
$$

The parameter $\alpha$ depends on exposure duration $(t){ }^{4}$

In our opinion, a fairly low correlation for matrices of only wrong answers is due to the fact that each object confusion matrix results from the pooling of data for several exposure durations of the stimuli. As Equation 12 shows, the ability of the visual system to discriminate the stimuli is determined not only by the distance between them, but also by the time of stimulus presentation. It is natural that, for some fixed distance, the probability of a wrong answer would be a nonlinear function of time. Therefore, for long exposure durations, a good discrimination would be obtained even if the interobject distance was small. Indeed, we obtained a rise (up to - .70) of correlation for matrices of only wrong answers, just as expected, when we took this parameter into account. Note that in the present study the correlation also rises if "I don't know"

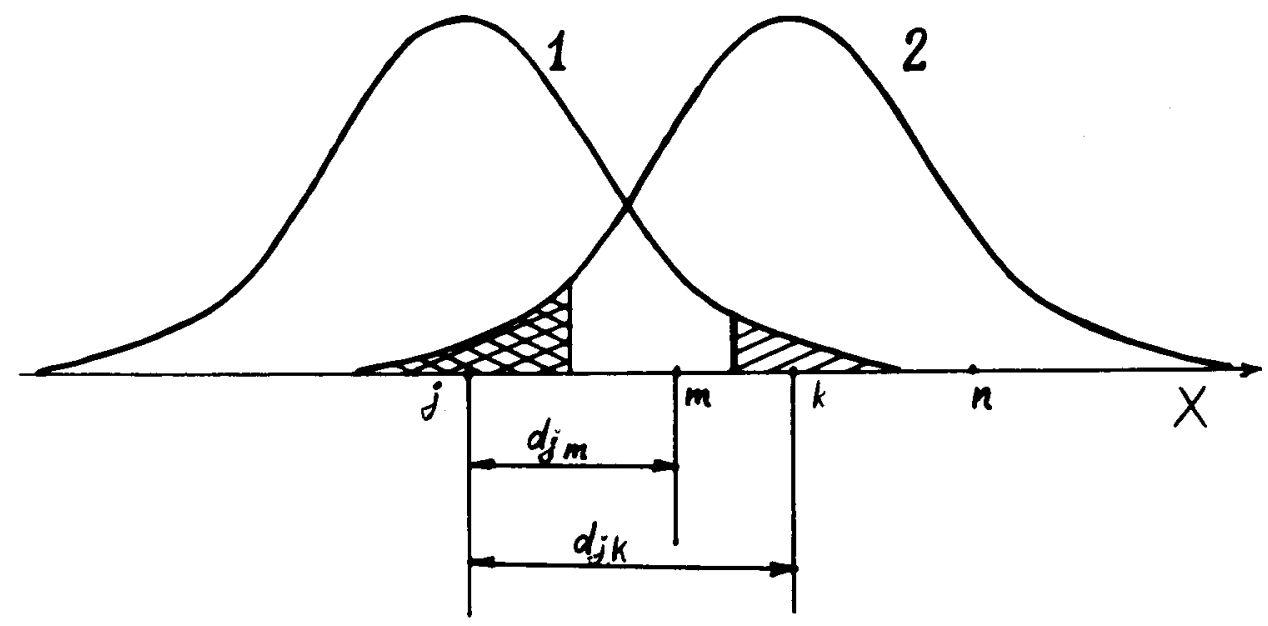

Figure 1. Probability distribution density of the visual system responses on the stimuli $j$ and $k$ presentations (Curves 1 and 2, correspondingly). $j, k, m$, and $n$ represent positions of the stimuli on the response axis $(X), d_{j k}$ and $d_{j m}$ are the distances between the $j$ and $k$ stimuli as well as between the $j$ and $m$ stimuli. The hatched and crosshatched areas under the response curves correspond to the probability of response $k$, stimulus $j$ being given as $P_{j k}$ and vice versa $\left(P_{k j}\right)$. Since $d_{j m}>d_{j k}-d_{j m}$, the probability $P_{j k}$ (hatched) will be less than $P_{k j}$ (crosshatched). 
answers are allowed (see Table 2, Subject I.E.): Correlation for this matrix of only wrong answers is -.49 (as compared with the similar value of -.31 obtained for Subject A.E.). From our point of view, this effect seems to be due to the fact that when "I don't know" answers are not allowed, an observer's response will in some cases be determined only by a vector of probability of only the a priori bias response $e_{j}$ rather than by the interobject distance (see Equation 12).

The idea of the predominant role of the phase spectrum in the recognition of visual patterns and scenes, as opposed to the role of the amplitude spectrum, has been put forward in a number of studies (Burgess \& Ghandeharian, 1984; Goodman \& Silvestri, 1970; Oppenheim \& Lim, 1981; Piotrowski, 1981). In our opinion, such an opposition is not likely to be right. It is known that objects with central symmetry have phase components identically equal to zero. However, the discrimination of such objects is not worse in comparison with that of nonsymmetrical ones, although their phase components are essentially distinct. The adherents of the phase hypothesis show, at the same time, a good discrimination of objects that differ only in the phase components.

Obviously, image analysis is performed in terms of the activity evoked in visual mechanisms by the stimuli. Within the framework of our approach, it suggests that this analysis is performed in terms of the full spectrum, while the role of the phase component itself is exhibited by the choice of an origin for the Fourier transform.

We suggest that our finding contrasts with the results of Coffin (1978), because Coffin did not take into account the dependence of the Fourier transform on the choice of an origin. It is just this peculiarity which, in our opinion, appears to be the most essential one for the measure of interobject distance suggested above. Support for the effect of the choice of the origin on visual signal discrimination comes from the findings of Burgess and Ghandeharian (1984). In their study, observers had to detect a two-cycle sine wave that just fitted into a static noise field or to discriminate two sinusoidal signals. Each trial also included a reference signal below the stimulus field. For trials "without phase information," the signals were identical except for the phase; the reference sine-wave phase was always zero, whereas the signal phase was randomly selected from 16 equally likely alternatives. For trials "with phase information," the reference and signal were identical in all respects. The best results were obtained when the signal phase was known. The authors concluded that "humans use phase information for detection and discrimination when sufficient a priori information is made available" (p. 900). From our point of view, the observer uses this information to make the correct choice of an origin of the reference frame, which is necessary for stimulus analysis. From the mathematical description of "phase-sensitive (cross-correlation) and phase-insensitive (autocorrelation) detection" considered by these authors, it follows that for trials " with phase information," the reference signal gives information only about the zero point.
As pointed out above, Gervais et al. (1984) used several models of visual processing to predict confusions among letter pairs. A function providing the highest correlation (.70) with the confusion data was selected for the model interletter distance. This function has the following form:

$$
\begin{aligned}
& D_{A B} \\
& \quad=\left\{\sum_{i j}\left[\left(\log X_{i j A}-\log X_{i j B}\right)\left(1+Y_{i j A}-Y_{i j B}\right)\right]^{2}\right\}^{1 / 2},
\end{aligned}
$$

where $X_{i j A}, X_{i j B}$ are the amplitudes of letters $A$ and $B$ in the amplitude spectrum filtered by a filter simulating the human two-dimensional contrast sensitivity function and $Y_{i j A}$ and $Y_{i j B}$ are the phases in the phase spectra of the letters $A$ and $B$, respectively. The only reason why such a function was preferred is that it provides a higher correlation than the other tested models do. In our opinion, it is unlikely that a function of such a form could be realized by any neurophysiological mechanism known.

On the contrary, with the function we choose for our model, interobject distance can be realized in a quite simple way by the visual receptive fields. We tried to formulate the distinctive properties of our model in terms of both amplitude and phase information, but it is not necessary to make complex nonlinear phase transformations (as the Gervais's model suggests) in order to calculate the interobject distances and to develop model responses. This is also true for the proposed choice of the spatial origin, which can be made by means of a simple comparison of the odd and even RF responses. This is the distinctive feature of the approach in the present study. The correlation attained by our model is equally high.

The various authors (Caelli, 1982; Coffin, 1978; Gervais et al., 1984) have taken into account in their models the human contrast sensitivity function, using it to filter the object amplitude spectrum. Our experimental results show that for our model it is not necessary, because correlations for object sizes $25^{\prime}$ and $1.64^{\circ}$ (the first stimulus set) appeared equally high, even though the spectral contents of these objects are essentially distinct. It is possible that this fact results from the suprathreshold conditions of our experiments (all the stimuli had a contrast of $65 \%$ ), and it is known that spatial frequency has little effect on contrast discrimination with suprathreshold gratings (Bradley \& Ohzawa, 1986).

Note that, as regards the contour figures of the second stimulus set, the spectral content was just barely significant. Filling in the contour figures redistributes the energy in favor of the spatial frequencies for which the period is comparable to the object size. The good correlation attained for these filled-in figures provides evidence that the information about a low spatial frequency part of the spectrum is sufficient for object shape recognition (see analogous data in Ginsburg, 1971, and Pavlovskaya et al., 1988). ${ }^{5}$

Consequently, it seems that a more adequate model of visual recognition should perhaps not be based on the Fourier integral but should rather take into account the real characteristics of the visual receptive fields-their finite sizes and the discrete character of the set of their 
spectral characteristics. It is precisely these properties which seem to determine the contrast sensitivity function (see Mostafavi \& Sakrison, 1976; Richards \& Polit, 1974; Wilson \& Bergen, 1979).

\section{REFERENCES}

ANDrews, B. W., \& Pollen, D. A. (1979). Relationship between spatial frequency selectivity and receptive field profile of simple cells. Journal of Physiology, 287, 163-176.

Blakemore, C. , CAMPBell, F. W. (1969). On the existence of neurones in the human visual system selectively sensitive to the orientation and size of retinal images. Journal of Physiology, 203, 237-260.

Bradley, A., \& OHzAWA, I. (1986). A comparison of contrast detection and discrimination. Vision Research, 26, $991-999$.

Burgess, A. E., Ghandeharian, H. (1984). Visual signal detection: 1. Ability to use phase information. Journal of the Optical Society of America, 1, 900-905.

Caeld, T. (1982). On discriminating visual textures and images. Perception \& Psychophysics, 31, 149-160.

Caelli, T., Hübner, M., Rentschler, I. (1986). On the discrimination of micropatterns and textures. Human Neurobiology, 5 , 129-136.

CAMPBELl, F. W., Robson, J. G. (1968). Application of Fourier analysis to visibility of gratings. Journal of Physiology, 197, 552-566.

Cofrin, S. (1978). Spatial frequency analysis of block letters does not predict experimental confusions. Perception \& Psychophysics, 23, 69-74.

De Valois, K. K., De Valois, R. L., Yund, E. W. (1979). Responses of striate cortex cells to grating and checkerboard patterns. Journal of Physiology, 291, 483-505.

Field, D. J., \& TolhuRst, D. J. (1986). The structure and symmetry of simple-cell receptive-field profiles in the cat's visual cortex. Proceedings of the Royal Society of London, B 228, 379-400.

Gervais, M. J., Harvey, L. O., \& RoberTs, J. O. (1984). Identification confusion among letters of the alphabet. Journal of Experimental Psychology: Human Perception \& Performance, 10, 655-666.

GinsBurg, A. P. (1971). Psychological correlates of a model of the human visual system. In Proceedings of the National Aerospace Electronics Conferences (NAECON), Dayton, Ohio (I.E.E.E Transactions on Aerospace Electronic Systems, pp. 283-290).

GLEZER, V. D. (1985). Spatial and spatial frequency characteristics of the receptive fields of the visual cortex. In D. Rose \& V. A. Dobson (Eds.), Models of the visual cortex (pp. 265-272). New York: Wiley.

Glezer, V. D., \& BorisovA, E. D. (1984). Time correlations of simple and complex features describing the visual image. Human Physiology, 10, 713-718. (In Russian)

Glezer, V. D., Gauzelman, V. E., \&akovlev, V. V. (1987). Moduli and basis function of the cat's visual cortex. Sensory Systems, 1, 100-109. (In Russian)

Glezer, V. D., Ivanov, V. A., \& Tsherbach, T. A. (1973). Investigation of complex and hypercomplex receptive fields of visual cortex of the cat as spatial frequency filter. Vision Research, 13, 1875-1904.

Glezer, V. D., Tsherbach, T. A., Gauzelman, V. E., \& Bondarko, V. M. (1980). Linear and non-linear properties of simple and complex receptive fields in area 17 of the cat visual cortex. Biological Cybernetics, 37, 195-208.

Goodman, J. W., Silvestri, A. M. (1970). Some effects of Fourierdomain phase quantization. IBM Joumal of Research \& Development, 14, 478-484.

Graham, N., \& Nachmias, J. (1971). Detection of grating patterns containing two spatial frequencies: A comparison of single-channel and multiple-channel models. Vision Research, 11, 251-259.

Harvey, L. O., JR., \&ervais, M. J. (1978). Visual texture perception and Fourier analysis. Perception \& Psychophysics, 24, 534-542.

KULIKOWSK, J. J., \& BISHOP, P. O. (1981). Linear analysis of responses of simple cells in the cat visual cortex. Experimental Brain Research, 44, 386-400.
LUCE, R. D. (1963). Detection and recognition. In R. D. Luce, R. R Buch, \& E. Galanter (Eds.), Handbook of mathematical psychology (pp. 103-189). New York: Wiley.

Maffei, L., Fiorentini, A. (1973). The visual cortex as a spatial frequency analyser. Vision Research, 13, 1255-1267.

MARĆE UA, S. (1980). Mathematical description of the responses of simple cortical cells. Joumal of the Optical Society of America, 70. 1297-1300.

Mostafavi, H., Sakrison, D. J. (1976). Structure and properties of a single channel in the human visual system. Vision Research. 16. 957-968.

Movshon, J. A., Thompson, I. D., Tolhurst, D. J. (1978). Spatial summation in the receptive field of simple cells in the cat's striate cortex. Journal of Physiology, 283, 53-77.

OPPENheim, A. V., LiM, J. S. (1981). The importance of phase in signals. Proceedings of the IEEE, 69, 529-542.

Pavlovskaya, M. B., Sivjakov, I. N., Makulov, V. B. (1988). Recognition of blurred and noised images. Human Physiology, 14. 795-805. (In Russian)

Plotrowski, L. N. (1981). The contributions of spatial-frequency amplitude and phase information for visual processing. In C. C. Jaffe (Ed.), 2nd Intermational Conference on Visual Psychophysics and Medical Imaging (pp. 49-51). New York: IEEE.

Pollen, D. A., Foster, K. H., Gaska, J. P. (1985). Phase-dependent response characteristics of visual cortical neurones. In D. Rose \& V. A. Dobson (Eds.), Models of the visual cortex (pp. 281-292). New York: Wiley.

Pollen, D. A., Lee, J. R., Taylor, J. H. (1971). How does the striate cortex begin the reconstruction of the visual world? Science, 173, 74-77.

Pollen, D. A., \& RonNer, S. F. (1982). Spatial computation performed by simple and complex cells in the visual cortex of the cat. Vision Research, 22, 101-118.

Prazdnikova, N. W. (1966). Investigation of the invariant object shape recognition. In V. D. Glezer (Ed.), Coding mechanisms of visual information (pp. 96-116). Moscow-Leningrad: Nauka. (In Russian)

Richards, W., \& Pout, A. (1974). Texture matching. Kybernetik, 16, 155-162.

SACHS, M. B., Nachmias, J., Robson, J. G. (1971). Spatial-frequency channels in human vision. Journal of the Optical Society of America, 61, 1176-1186.

Sullivan, G. D., Georgeson, M. A., OAtley, K. (1972). Channels for spatial frequency selection and the detection of single bars by the human visual system. Vision Research, 12, 383-394.

Vol, I. A., \& PAvlovskaya, M. B. (1987). A statistical model for visual recognition based on the similarity between Fourier transforms of images. Perception, 16, 248.

Vol, I. A., Pavlovskaya, M. B. (1988). A statistical visual recognition model based on Fourier transforms of objects. Sensory Systems, 2, 47-58.

Wilson, H. R., BerGen, J. K. (1979). A four-mechanism model for threshold spatial vision. Vision Research, 19, 19-32.

\section{NOTES}

1. The textures were synthesized by combining various spatial frequencies of different amplitudes.

2. Of course, the more advanced models of visual recognition should take into account these characteristics. In this case, the term Fourier processing would be only a label.

3. It is known that there is an invariant object shape recognition among dogs, cats, and monkeys, for both contour figures and figures that are filled in (Prazdnikova, 1966).

4. This model is discussed in detail by Vol and Pavlovskaya (1987, 1988)

5. It should be noted that the predominant energy of any stimulus in our first set is also contained in the low-frequency part of the spectrum.

(Manuscript received November 6, 1987; revision accepted for publication June 16,1989 ). 